\title{
Synergistic Effect of Dazomet Soil Fumigation and Clonostachys rosea Against Cucumber Fusarium Wilt
}

\author{
Tian Tian, Shi-Dong Li, and Man-Hong Sun
}

Key Laboratory of Integrated Pest Management in Crops, Ministry of Agriculture, Institute of Plant Protection, Chinese Academy of Agricultural Sciences, Beijing 100081, China.

Accepted for publication 6 June 2014.

\section{ABSTRACT}

Tian, T., Li, S.-D., and Sun, M.-H. 2014. Synergistic effect of dazomet soil fumigation and Clonostachys rosea against cucumber Fusarium wilt. Phytopathology 104:1314-1321.

Soil fumigation and biological control are two control measures frequently used against soilborne diseases. In this study, the chemical fumigant dazomet was applied in combination with the biocontrol agent (BCA) Clonostachys rosea 67-1 to combat cucumber wilt caused by $\mathrm{Fu}$ sarium oxysporum f. sp. сиситеrinum KW2-1. When the mycoparasite C. rosea 67-1 was applied after dazomet fumigation, disease control reached $100 \%$, compared with 88.1 and $69.8 \%$ for dazomet and $67-1$ agent, respectively, applied alone, indicating a synergistic effect of dazomet and $C$. rosea in combating cucumber Fusarium wilt based on analysis of
Bliss Independence. To understand the synergistic mechanism, the effects of chemical fumigation on the colonization potential and activity of $F$. oxysporum f. sp. cucumerinum, and the interaction between the BCA and the pathogen were investigated. The results showed that growth of the pathogen decreased with increasing dazomet concentration subsequent to fumigation. When exposed to dazomet at $100 \mathrm{ppm}$, the fungal sporulation rate decreased by $94.4 \%$. Severe damage was observed in fumigated isolates using scanning electron microscopy. In the greenhouse, disease incidence of cucumber caused by fumigated $F$. oxysporum f. sp. $\mathrm{cu}$ cumerinum significantly decreased. Whereas germination of $C$. rosea 67-1 spores increased by $>$ sixfold in fumigated soil, and its ability to parasitize fumigated $F$. oxysporum $\mathrm{f}$. sp. cucumerinum significantly increased $(P=$ $0.014)$.
Cucumber wilt, caused by Fusarium oxysporum f. sp. cucumerinum J. H. Owen, is a widespread soilborne disease, which can cause serious damage and great economic losses to cucumber production worldwide. In recent years, protected vegetable production has increased rapidly in China. However, long periods of continuous cropping accompanied by high-density propagation and intensified fertilization can trigger continuous cropping obstacles, which lead to changes in the soil microflora, accumulation of pathogens, and, eventually, disease outbreaks. At present, Fusarium wilt has become one of the major barriers to protected cucumber production in China.

Several measures have shown promising results in suppressing cucumber Fusarium wilt and improving overall yields $(23,41,43)$, in which fumigation is frequently used in the greenhouse. Soil sterilization using chemical fumigants such as dichloropropene, dazomet, organic sulfur, and biofumigants can exterminate various pests and eliminate pathogenic soil microorganisms rapidly and efficiently. The fumigants volatilize soon afterward and do not contaminate the agricultural products $(2,12,19,37,49)$. Dazomet (3,5-dimethyl-1,3,5-thiadiazine-2-thione) decomposes into methyl isothiocyanate (MITC) in moist soil, preventing soilborne diseases. Previous studies have shown that, by mixing soil or furrow applications, dazomet fumigation can suppress many soilborne diseases effectively and, thus, increase crop yield $(21,25,29,48)$. Mao et al. (31) found that the population density of $F$. oxysporum decreased $93.1 \%$ after treatment with $98 \%$ dazomet prior to planting cucumber in a nursery garden. However, pathogens can potentially reproduce following soil fumigation, and a subsequent invasion could be serious (14). There is some evidence that

Corresponding author: M.-H. Sun; E-mail address: sunmanhong2013@163.com

http://dx.doi.org/10.1094/PHYTO-11-13-0297-R

(c) 2014 The American Phytopathological Society repeated use of chemical fumigants in the soil may result in a decreased ability to control soilborne diseases over time $(15,47)$. Several studies have been conducted to analyze the effects of various fumigants on rhizospheric microorganisms, soil physicochemical and enzymatic characteristics, and different practices on microflora and microbial ecology in soil $(13,24,33,38,54)$.

Biological control has played an increasingly important role in the suppression of plant fungal diseases and organic vegetable production. Several commercial biocontrol agents (BCAs)Trichoderma viride Trieco, Bacillus GB03, MBI600, and FZB24-have been applied successfully to control Fusarium wilt $(4,7)$. A promising mycoparasite, Clonostachys rosea, has also shown great potential in countering many plant fungal pathogens and increasing crop yield $(8,9,26,35,36,56)$. However, inconsistent results have often been observed in field trials in different areas for BCAs, especially in seriously infected soil $(25,42,44)$.

Combining the two practices (fumigation and biological control) has been attempted to manage soilborne plant diseases in the field (17,20,44-46). When treated with high-efficiency, lowtoxicity chemical fumigants, adverse factors in soil were found to be weakened or eliminated, and favorable conditions were created for the introduction and colonization of beneficial microorganisms (32,34). Slusarski and Pietr (46) found that, after using dazomet and Trichoderma sp. B35 continuously for 3 years, the incidence of Verticillium wilt on green pepper dropped sharply to $1.8 \%$ in the greenhouse. However, the relationship among fumigant, biocontrol fungus, and pathogen is unclear, and the synergistic mechanism of soil fumigation and biological control needs to be demonstrated. Paret et al. (39) studied the variation in cell structure and chemical components of Ralstonia solanacearum by using micro-Raman spectroscopy and electron microscopy, and indicated that fumigation could lead to the loss of nutrients and injury to the cell wall of the pathogen. Therefore, these authors theorized that fumigation might result in a decrease 
in the pathogenicity of $P$. solanacearum. However, no direct evidence of this was provided. Several biological traits were also regarded to be related to fungal pathogenicity. $\beta$-D-glucosaccharase is an important type of cellulase, and previous studies have shown that the enzyme activity and pathogenicity were closely correlated in $F$. oxysporum $(5,6,52)$. When induced by host plants, the pathogen can secrete a series of cell-wall-degrading enzymes, including $\beta$-D-glucosaccharase, which enables $F$. oxysporum to penetrate and parasitize crop plants. Cumagun (11) found that the red pigment production gene PIGl in Gibberella zeae (anamorph $F$. graminearum) closely linked to disease severity. However, the impact of fumigation on these virulence-related characteristics is scarcely touched.

In order to evaluate the synergistic effect of fumigation and biological control in disease management, an efficient and lowtoxicity chemical fumigant, dazomet, and a promising mycoparasite, $C$. rosea 67-1, were chosen to determine their effects on cucumber Fusarium wilt in the greenhouse. The effects of the fumigant on the colonization potential, the activity of the pathogen, and the interaction between the biocontrol isolate and the pathogen were studied. Understanding the synergistic effect of soil fumigants and beneficial microbes in countering plant pathogens will help establish a theoretical foundation for the effective use of BCAs against soilborne diseases.

\section{MATERIALS AND METHODS}

Isolates. $C$. rosea $67-1$ was originally isolated from vegetable garden soil obtained from Ledong Farm in Hainan Province, China using a sclerotia baiting method (55) and identified by the Institute of Microbiology, Chinese Academy of Sciences based on its colony morphology and microscopic characteristics. The $F$. oxysporum f. sp. cucumerinum KW2-1 isolate used in these studies was isolated from a protected cucumber-growing facility in Langfang, Hebei Province, China. Both strains are maintained in the Biocontrol of Soilborne Diseases Lab of the Institute of Plant Protection, Chinese Academy of Agricultural Sciences (CAAS).

Plant materials. The cucumber 'Zhongnong \#6' was provided by the Institute of Vegetables and Flowers, CAAS. This cultivar is rated as moderately susceptible to $F$. oxysporum f. sp. cucumerinum (30).

Agents. The soil fumigant, $98 \%$ dazomet powder, was provided by the Applied Microbiology Lab of the Institute of Plant Protection, Shanghai Academy of Agricultural Sciences.

Media. Millet-rice husk medium was prepared by mixing millet and rice husks $(1: 1, \mathrm{vol} / \mathrm{vol})$ thoroughly. Water was added to maintain appropriate moisture $(\approx 25$ to $30 \%)$ and the substrate mixture was put into glass jars to fill one-third of the volume. Basal medium consisted of $25.0 \mathrm{~g}$ of glucose, $7.2 \mathrm{~g}$ of yeast extract powder, $0.5 \mathrm{~g}$ of NaCl, $1.0 \mathrm{~g}$ of $\mathrm{K}_{2} \mathrm{HPO}_{4}, 0.5 \mathrm{~g}$ of $\mathrm{MgSO}_{4}$. $7 \mathrm{H}_{2} \mathrm{O}, 50 \mathrm{mg}$ of $\mathrm{ZnSO}_{4} \cdot 7 \mathrm{H}_{2} \mathrm{O}, 50 \mathrm{mg}$ of $\mathrm{FeSO}_{4} \cdot 7 \mathrm{H}_{2} \mathrm{O}$, and $1,000 \mathrm{ml}$ of distilled water. The $\mathrm{pH}$ of the broth was then adjusted to 6.5 . Both media were sterilized at $121^{\circ} \mathrm{C}$ for $30 \mathrm{~min}$.

Preparation of soil infested with $F$. oxysporum f. sp. cucumerinum. A culture of $F$. oxysporum f. sp. cucumerinum KW2-1 was inoculated on potato dextrose agar (PDA) and incubated at $26^{\circ} \mathrm{C}$ for 7 to 10 days. The fungal culture was cut into 5-mm blocks with a sterile knife and inoculated into sterile millet-rice husk medium. Each plate was divided and transferred to two jars. The fungus and substrate were mixed thoroughly, and cultured in an incubator at 25 to $30^{\circ} \mathrm{C}$ for 10 days. KW2-1 inoculum was mixed into the soil collected from an uninfested vegetable yard at a rate of $3 \%(\mathrm{wt} / \mathrm{wt})$, which corresponded to $6 \times$ $10^{5} \mathrm{CFU} / \mathrm{g}$ of soil, and put in 64-by-38-cm plastic boxes. Ten cucumber seedlings, preplanted in a nursery garden for 14 days, were transferred into the $F$. oxysporum f. sp. cucumerinuminfested soil in each box. After the symptoms of wilt fully developed, the plants were pulled out. The soil in each box was remixed completely, dried, and passed through a $2-\mathrm{mm}$ pore-size sieve to get rid of plant residues.

Preparation of inoculants of $C$. rosea 67-1. The $C$. rosea $67-1$ isolate was cultured on PDA plates at $26^{\circ} \mathrm{C}$. After 10 days, $5 \mathrm{ml}$ of sterile distilled water was added to the plates to elute fungal spores with a sterile glass spatula. The spore suspension was inoculated into basal broth in a 500-ml flask, and cultured on a fermentation shaker at a speed of $180 \mathrm{rpm}$. The fungus was incubated at $26^{\circ} \mathrm{C}$ for $72 \mathrm{~h}$, to prepare the inoculum of isolate 67-1.

Combined control of cucumber Fusarium wilt with dazomet and $C$. rosea in the greenhouse. Four treatments were included in the experiment: (i) fumigation with dazomet; (ii) biocontrol with $C$. rosea 67-1; (iii) $C$. rosea 67-1 inoculation after fumigation with dazomet; and (iv) the control, which received infested soil only. The soils with different treatments were put into plastic pots $(15 \mathrm{~cm}$ in diameter), and cucumber seedlings that had been grown for 14 days were transferred into the pots and evaluated for the control efficiency of the four different treatments in the greenhouse. For fumigation, 98\% dazomet powder was mixed with $F$. oxysporum f. sp. cucumerinum-infested soil $(1: 1,000, \mathrm{wt} / \mathrm{wt})$ and put into the boxes. Water was added to reach $24 \%$ moisture content, and the boxes were sealed with $0.06-\mathrm{mm}$ plastic film immediately and maintained at 25 to $28^{\circ} \mathrm{C}$ in the greenhouse for 10 days. The soil was turned twice during this period. After fumigation, the film was removed and the soil was loosened to release chemical gases. After aerating for 7 days, the soil was used as fumigated soil. For biocontrol, $C$. rosea agent was applied into the holes in F. oxysporum f. sp. cucumerinuminfested soil when transplanting. Three 5 -cm-deep holes were dug in each pot and 67-1 culture broth together with a cucumber seedling and $\approx 20 \mathrm{~g}$ of growing substrates were transferred into the holes simultaneously. The concentration of 67-1 inoculum was $2 \times 10^{7} \mathrm{CFU} /$ hole. For fumigation with biocontrol, the $C$. rosea $67-1$ isolate was inoculated into fumigated soil at $2 \times 10^{7} \mathrm{CFU} /$ hole during transplant. The growing temperature was 26 to $30^{\circ} \mathrm{C}$ during the day and $15^{\circ} \mathrm{C}$ at night. There were three seedlings per pot, and eight pots per treatment. Pots were arranged in a randomized complete block design with three replicates for each treatment.

All of the seedlings were investigated for the incidence and severity of Fusarium wilt on cucumber after 45 days, and the control efficiencies of the different treatments were evaluated. Disease indices were rated using a five-level grading scale (from 0 to 4 ) based on symptoms on leaves and stems (16). Grade $0=$ no wilting symptoms observed; grade $1=$ wilting only on a few leaves; grade 2 = slight wilting, necrotic spots appearing on the stem, and presence of chlorosis; grade $3=$ moderate wilting, drooping leaves and chlorosis; and grade $4=$ extensive wilting, lodging, and withering. The expected control efficacy for combined use of the two measures was estimated using the model of Bliss Independence (i.e., $E_{12}=E_{1}+E_{2}-E_{1} \times E_{2}$, where $E_{1}$ and $E_{2}$ were the efficacy of the two individuals). The observed control efficacy for combined use $\left(O_{12}\right)$ was compared with $E_{12}$, and the interactions among the two practices were judged as follows: if $O_{12}>E_{12}$, then synergistic interaction was indicated; if $O_{12}=E_{12}$, no interaction (i.e., additive effect) existed; and if $O_{12}<E_{12}$, an antagonistic interaction was implied (3).

Effect of fumigation on growth of $F$. oxysporum f. sp. cucumerinum KW2-1. Soil was collected from the top 0 to $20 \mathrm{~cm}$ of the ploughed layer in the experimental field at the Institute of Plant Protection of the CAAS in Langfang. The preceding crop was tomato. Soil was passed through a $1-\mathrm{mm}$ sieve, and $500 \mathrm{~g}$ was put into a glass jar and dry-heat sterilized at $162^{\circ} \mathrm{C}$ in an oven for $5 \mathrm{~h}$. Dazomet was added at the effective concentrations of 25, 50,75 , and $100 \mathrm{ppm}$. The soil was mixed thoroughly, and $120 \mathrm{ml}$ of sterile water was added to keep the water content at $24 \%$. From 
the edge of the agar plate, a 5-mm disk of KW2-1 cultured for 10 days was transferred to a fresh PDA plate, and the petri dish was upended on the jar immediately. The upside-down plate was sealed at the bottleneck with Parafilm to avoid escape of the effective compounds from fumigation. The pathogenic $F$. oxysporum f. sp. cucumerinum culture was incubated at $26^{\circ} \mathrm{C}$ for 7 days, after which the morphology of the colony was observed and the growth rate was determined. Each treatment was replicated three times.

Morphology of spores and hypha of the fumigated $F$. oxysporum f. sp. cucumerinum KW2-1-F isolate. The KW2-1 isolate treated with dazomet was transferred to a fresh PDA plate and marked as KW2-1-F. After growing at $26^{\circ} \mathrm{C}$ in an incubator for 7 days, $5 \mathrm{ml}$ of sterile distilled water was added to elute fungal spores with a sterile glass spatula, and the spore suspension was collected. Fungal mycelia on another agar plate were also collected. The samples were processed as described by Pisi et al. (40), and photos were taken with a scanning electron microscope (Hitachi S-570).

Sporulation of $F$. oxysporum f. sp. cucumerinum KW2-1-F. A 5-mm agar disk of the dazomet-treated isolate $\mathrm{KW} 2-1-\mathrm{F}$ was inoculated onto the center of PDA plate and incubated at $26^{\circ} \mathrm{C}$ for 7 days. The spores were eluted with $5 \mathrm{ml}$ of sterile distilled water, and the suspension was collected and diluted. The number of spores was counted under a microscope using a hemocytometer. The original strain KW2-1 was used as a control. Three replicates were used for both isolates.

Pigment production by KW2-1-F. The concentration of the KW2-1-F spore suspension obtained from the agar plate was adjusted to $1 \times 10^{6}$ spores $/ \mathrm{ml}$ by dilution with sterile water. The spore suspension $(5 \mathrm{ml})$ was inoculated into $50 \mathrm{ml}$ of pigmentproducing liquor in a $250-\mathrm{ml}$ flask and cultured on a shaker at a speed of $200 \mathrm{rpm}$. After incubating at $28^{\circ} \mathrm{C}$ for 5 days, the pigment in the fungal cells was extracted by ultrasonic disruption, and the color value was determined at $520 \mathrm{~nm}$ with an ultraviolet spectrophotometer (10). Three replicates were used.

Activity of $\beta$-D-glucosaccharase activity in KW2-1-F. $\beta$-Dglucosaccharase was extracted from $F$. oxysporum and its activity was determined. A spore suspension of the fumigated strain was prepared as described above, and $1 \mathrm{ml}$ of the suspension was inoculated into $100 \mathrm{ml}$ of potato sucrose broth. The culture was then shaken at $25^{\circ} \mathrm{C}$ at a speed of $120 \mathrm{rpm}$ for 7 days, filtered through a double layer of cheesecloth to remove fungal hyphae, and centrifuged at $10,000 \mathrm{rpm}$ for $20 \mathrm{~min}$ to obtain a crude enzyme preparation. The activity of $\beta$-D-glucosaccharase was determined by a spectrophotometer according to Che et al. (5).

Effect of KW2-1-F on germination of cucumber seed and shoot growth. Plump cucumber seed were selected and heated at $60^{\circ} \mathrm{C}$ in an oven for $5 \mathrm{~h}$. A spore suspension $(1.5 \mathrm{ml})$ of $\mathrm{KW} 2-1-\mathrm{F}$ $\left(1 \times 10^{6}\right.$ spores $\left./ \mathrm{ml}\right)$ was applied to coat the seed, and the seed were stirred intermittently during the presoaking. After $3 \mathrm{~h}$, the cucumber seed were placed on wet sterile filter paper in a petri dish and cultured at $25^{\circ} \mathrm{C}$ in a lighted incubator. Germination rates were recorded. Seed soaked in a spore suspension of KW2-1 and water were used as controls. Thirty seeds were included in each treatment, and five replicates were used.

Pathogenicity of KW2-1-F on cucumber. Cucumber seed were preheated as described above and soaked in sterile water for $3 \mathrm{~h}$. The seed were then placed on wet filter paper in sterilized culture dishes to accelerate germination. After $12 \mathrm{~h}$, the germinated seed were sown in a 50:50 mixture of nutrient soil and vermiculite that had been dry-heat sterilized at $163^{\circ} \mathrm{C}$ for $5 \mathrm{~h}$. Ten days after sprouting, the cucumber seedlings were pulled out, the soil attached to the roots was washed off, and the seedlings were then immersed into the KW2-1-F and KW2-1 spore suspensions $\left(1 \times 10^{6} \mathrm{spores} / \mathrm{ml}\right)$ for $15 \mathrm{~min}$. The seedlings were transplanted into sterile nutrient substrate in paper cups $(10 \mathrm{~cm}$ in diameter), two seedlings per cup. The plants were grown in a lighted incubator with $12 \mathrm{~h}$ of illumination at $26^{\circ} \mathrm{C}$. There were five cups per treatment, with five repeats per treatment. Fourteen days after planting, the incidence of Fusarium wilt on cucumber in both treatments was determined. The disease severities were graded on a scale of 0 to 4 where grade $0=$ no browning; grade $1=$ slight infection, brown areas covering $<25 \%$ of the root and the basal part of the stem; grade $2=$ brown areas covering 25 to $50 \%$ of the root and the basal part of the stem; grade $3=$ brown areas covering 50 to $75 \%$ of the root and the basal part of the stem; and grade $4=$ extensive wilting, with browning covering $>75 \%$ of the root and the basal part of the stem.

Effect of soil fumigation on fungistasis to the biocontrol fungus. Soil collected from the vegetable yard was mixed thoroughly with $0.1 \%(\mathrm{wt} / \mathrm{wt})$ dazomet powder. The mixture was put into plastic trays ( 15 by 10 by $5 \mathrm{~cm}$ ), watered, and covered with a plastic mulch film. After fumigating for 5 days, the soil was uncovered and air dried. The soil was then screened through a $0.38-\mu \mathrm{m}$ sieve, and $20 \mathrm{~g}$ was put into a sterile plate $(90 \mathrm{~mm}$ in diameter) and moistened with 10 to $20 \mathrm{ml}$ of sterile distilled water. Two pieces of sterile cellophane, 30 by $30 \mathrm{~mm}$ and 10 by $10 \mathrm{~mm}$, were placed on the surface of the soil in succession. Spores of $C$. rosea 67-1 were collected and washed twice by centrifugation with sterile water to remove nutrients. The spores were dropped in the center of the upper cellophane with a concentration of $\approx 30$ to 50 spores per microscope field, and were then covered with a piece of 30-by-30-mm cellophane and a layer of 0.5 to $1 \mathrm{~cm}$ of fumigated soil. The soil was kept moist and incubated at $25^{\circ} \mathrm{C}$ for $8 \mathrm{~h}$; the cellophane with the droplet of $67-1$ spores was then removed and examined under a microscope for spore germination. PDA medium and untreated soil were used as controls, and three replicates were used.

Mycoparasitism of the biocontrol isolate $C$. rosea 67-1 on $F$. oxysporum f. sp. cucumerinum. A piece of a sterile microscope slide was placed on two glass bars in a 9-cm-diameter petri dish. A nutrient-deficient medium (1/4× PDA) was melted, and $10 \mu \mathrm{l}$ was dropped in the center of the slide glass with a pipette (Gilson, France) and smeared evenly with a sterile glass scraper to form a 20-by-20-mm thin film. Small agar blocks $(2 \mathrm{~mm})$ containing $C$. rosea $67-1$ and $F$. oxysporum $\mathrm{f}$. sp. cucumerinum KW2-1-F were placed on opposite sides of the film. The plate was sealed with Parafilm to maintain moisture and incubated at $25^{\circ} \mathrm{C}$. When the colonies of the biocontrol fungus and pathogenic fungus grew into each other, the slides were lifted and mounted on a microscope with a 10-by-10 net eyepiece micrometer (Olympus BX51, Japan). The microstructure and interaction between the two fungi were observed under a microscope at $\times 400$ magnification.

The numbers of $F$. oxysporum hyphae at each intersection of the micrometer grid were determined, and the mycelia of $C$. rosea 67-1 that were attached to or bound to the $F$. oxysporum f. sp. cucumerinum hyphae were regarded as parasitic. Three random fields were examined. The original pathogenic strain KW2-1 with C. rosea 67-1 was the control. Three replicates were used for each treatment.

Statistical analysis. SPSS Statistics V17.0 software (IBM Corporation) was used for statistical comparisons of the treatments. Analysis of variance and $t$ tests were used for comparisons of the means from each treatment, and regression was used for the study of a quantitative factor.

\section{RESULTS}

Integrated control of cucumber Fusarium wilt by dazomet and $C$. rosea in the greenhouse. Dazomet fumigation was an efficient practice for suppressing Fusarium wilt disease on cucumber caused by F. oxysporum, as was application of the biocontrol fungus $C$. rosea $67-1$. Both methods significantly reduced the population of the pathogen in soil $(P<0.01)$. Dazomet 
fumigation followed by $C$. rosea 67-1 application decreased the density of $F$. oxysporum in soil by $98.8 \%$, and provided a control efficiency of Fusarium wilt of $100 \%$ (Table 1). Based on the respective control efficiency of soil fumigation and biocontrol with three replicates, the expected control efficacy for combined use of the two measures was calculated $\left(E_{12}=E_{1}+E_{2}-E_{1} \times E_{2}\right)$. The expected measurement of $96.4 \%$ was lower than the actual measurement $(P=0.02)$, indicating that there was a synergistic effect of dazomet and $C$. rosea in combating cucumber Fusarium wilt according to the analysis of Bliss Independence.

Effect of fumigation on growth of $F$. oxysporum $f$. sp. cucumerinum KW2-1. After dazomet fumigation, the growth of F. oxysporum f. sp. cucumerinum KW2-1 was increasingly suppressed with increasing concentrations of the effective components in the fumigant. The regression equation was $y=-0.0618 x+$ 9.676, with the correlation coefficient $\left(R^{2}\right)$ of 0.986 . When the pathogenic fungus was exposed to soil mixed with dazomet at $100 \mathrm{ppm}$, the extension of fungal hypha decreased by $67.1 \%$ (Fig. 1). In this study, the fungus treated with dazomet at $100 \mathrm{ppm}$ was considered to be the fumigated isolate and was named KW2-1-F.

Morphology of the fumigated isolate KW2-1-F. Isolate KW2-1 grew rapidly, forming thick hyphae and an obvious purple zone. However, KW2-1-F that had been treated with dazomet displayed slow, weak growth. There were fewer aerial hyphae and no distinct pigment zone was present. The microstructures of the pathogens with and without fumigant treatment showed significant differences under scanning electron microscopy. The cells of KW2-1 spores and mycelia were active, with intact cell walls and visible lipid droplets. Intracellular structures were distinct, with clear and smooth boundaries (Fig. 2A and C). In contrast, cells of KW2-1-F appeared to be distressed. Most of the cells were shrunken and deformed, and some appeared empty. Lysis of organelles and release of cell contents were observed, which meant that the pathogenic fungus had been inactivated (Fig. 2B, $\mathrm{D}$, and $\mathrm{E}$ )

Biological characteristics of KW2-1-F. When the pathogen isolate KW2-1 was treated with dazomet, its biological characteristics changed drastically. Chemical fumigation reduced the sporulation level of $F$. oxysporum f. sp. cucumerinum by $94.4 \%$, and a comparison of the pigment yields between the original isolate and KW2-1-F were significantly different $(P<0.01)$. The activity of $\beta$-D-glucosaccharase in KW2-1-F decreased by $54.2 \%$ compared with KW2-1, which indicated that virulence of $F$. oxysporum might be negatively affected as well (Table 2).

Effect of KW2-1-F on germination of cucumber seed and growth of shoots. After soaking in spore suspensions of $F$. oxy-

TABLE 1. Control of cucumber Fusarium wilt by dazomet and Clonostachys rosea in the greenhouse ${ }^{\mathrm{z}}$

\begin{tabular}{lccc}
\hline & $\begin{array}{c}\text { Fusarium } \\
\text { oxysporum } \\
\text { Treatment }\end{array}$ & $\begin{array}{c}\text { Disease index } \\
(\%)\end{array}$ & $\begin{array}{c}\text { Control } \\
\text { efficiency (\%) }\end{array}$ \\
\hline Dazomet & $526 \pm 5 \mathrm{~A}$ & $7.5 \pm 1.5 \mathrm{~A}$ & $88.1 \pm 2.2 \mathrm{~A}$ \\
$67-1$ & $1,018 \pm 87 \mathrm{~B}$ & $19.0 \pm 1.4 \mathrm{~B}$ & $69.8 \pm 1.8 \mathrm{~B}$ \\
Dazomet $+67-1$ & $53 \pm 12 \mathrm{C}$ & $0.0 \pm 0.0 \mathrm{C}$ & $100.0 \pm 0.0 \mathrm{C}$ \\
Control & $4,401 \pm 56 \mathrm{D}$ & $63.0 \pm 2.8 \mathrm{D}$ & $\ldots$ \\
\hline
\end{tabular}

${ }^{\mathrm{z}}$ Data are means \pm standard deviations of populations of $F$. oxysporum in soil, disease indices of Fusarium wilt of cucumber, and control efficiencies for different methods, including fumigation with $98 \%$ dazomet powder ( $1 \mathrm{~g} / 1,000 \mathrm{~g}$ soil), C. rosea $67-1\left(2 \times 10^{7} \mathrm{CFU} / \mathrm{hole}\right)$, dazomet + C. rosea $67-1$, and the control (without fumigant and biocontrol fungus). Treatments were examined 45 days after cucumber seedlings were transplanted into 15 -cm-diameter plastic pots in the greenhouse. There were three replicates of eight pots with three seedlings in each, with each treatment in a randomized complete block design. The temperatures were 26 to $30^{\circ} \mathrm{C}$ during the day and $15^{\circ} \mathrm{C}$ at night. Values within a column followed by the same letter are not significantly different $(P<0.01)$ according to Duncan's multiple range test. sporum f. sp. cucumerinum KW2-1 or KW2-1-F, the germination rate of cucumber seed decreased slightly compared with the seed soaked in water. However, there was no significant difference among the three treatments. The growth of cucumber shoots infected by KW2-1 was greatly inhibited compared with both the water control and the fumigated isolate $(P<0.01)$ (Table 3$)$. The seedlings treated with KW2-1 were coated with white mycelia, and the plants withered and died in $120 \mathrm{~h}$. There were few mycelia observed on the plants treated with KW2-1-F, and the growth of seedlings was healthy.

Pathogenicity of KW2-1-F on cucumber. Of the cucumber seedlings infected with $F$. oxysporum, the development of symptoms of Fusarium wilt were significantly different between inoculations with spore suspensions of KW2-1 and KW2-1-F $\left(10^{6}\right.$ spores $/ \mathrm{ml}$ ) on young roots. Fourteen days after transplanting, $>70 \%$ of seedlings treated with the original strain showed typical wilt symptoms: the basal part of the stem turned brown accompanied by occasional constriction, and leaves were droopy and yellowed to the extent that $36 \%$ of the plants withered. On the other hand, only slight spots were observed on the seedlings soaked in the KW2-1-F spore suspension (Table 4).

Effect of soil fumigation on fungistasis to $C$. rosea 67-1. Fungistasis is a key factor that affects the activity and colonization of BCAs. Fungistasis to $C$. rosea 67-1 was greatly decreased after dazomet fumigation $(P<0.01)$. The germination rate of $67-1$ spores reached $68.0 \pm 3.0 \%$ in fumigated soil whereas, in natural soil, the rate was only $10.3 \pm 1.2 \%$, indicating that the soil environment improved for colonization of the biocontrol fungus; thus, the BCA was able to play a more active role in the control of soilborne diseases.

Mycoparasitism of $C$. rosea 67-1 on $F$. oxysporum f. sp. cucumerinum KW2-1-F. Our results demonstrate that the endurance of fumigated pathogen to C. rosea decreased compared with the unfumigated isolate. After side-by-side cultivation for 3 days, the isolates of $C$. rosea $67-1$ and $F$. oxysporum KW2-1-F grew together on the agar slide. Soon afterward, the colonies connected and extended into one another. It was obvious that the colony of C. rosea 67-1 was dominant in the contact zone. Under a microscope, it could be seen that the hyphae of 67-1 attached and spread along the hyphae of the pathogenic fungus in parallel or in wave form. In some cases, the hyphae of both species bonded with each other closely. The rate of $C$. rosea 67-1 hyphae contacting and binding with $F$. oxysporum f. sp. cucumerinum KW2-1-F hyphae was much greater than with KW2-1 (Table 5).

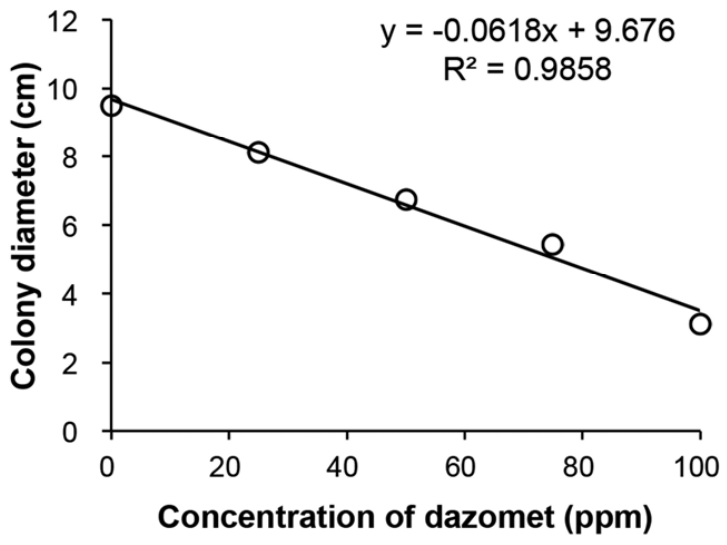

Fig. 1. Regression analysis of hyphal growth of the fumigated isolate of Fusarium oxysporum KW2-1 versus dazomet concentration. Data points were averages of colony diameter, in centimeters, of $F$. oxysporum f. sp. cucumerinum grown on potato dextrose agar, exposed to different dosages of dazomet mixed with sterile field soil and $24 \%$ water. Incubation was at $26^{\circ} \mathrm{C}$ for 7 days with three replicates. 


\section{DISCUSSION}

Biocontrol is regarded as a promising and environmentally friendly strategy for plant protection, and has been widely applied in managing various plant diseases. However, for a nonindigenous $\mathrm{BCA}$, it is much harder to compete with native soil inhabitants and, therefore, unstable results are often observed in different environmental conditions in the field $(28,46)$. Fungistasis, which hinders the germination and colonization of soil microorganisms, is a major factor for BCAs to be considered. Previous studies have demonstrated that fungistasis is related not only to nutrient deficiency but also to soil microbial flora $(18,51)$. In protected fields where vegetables are successively planted over several seasons, the soil habitat breaks down because of the accumulation of harmful microorganisms and their toxins, and the problem of fungistasis becomes very serious under these conditions. In our research, an obvious decrease in fungistasis to the biocontrol fungus $C$. rosea 67-1 was achieved through soil pretreatment with the highly efficient, low-toxicity chemical fumigant dazomet, and the germination rate of 67-1 spores in the fumigated soil substrate approached $70 \%$. Through soil fumigation, pests were killed and the effect of fungistasis was eliminated or weakened (34); thus, it was more likely that BCAs could colonize in the soil. Furthermore, it is very important to establish a new, healthy environment that benefits plant growth and suppresses pathogen propagation through the use of biocontrol microorganisms that can rapidly fill the temporary biological vacuum in soil caused by fumigation. In our study, the application of $C$. rosea combined with dazomet fumigation achieved essentially $100 \%$ control efficiency on cucumber Fusarium wilt, which was much higher than the individual control efficiencies of the two agents used alone. This conclusion is consistent with the results of Slusarski and Pietr (46).

Bliss Independence is a statistical model to analyze the effects of multiple factors (3), and it has been used to evaluate the effects of interactions among BCAs on disease development $(22,53)$. When several BCAs or different management practices are used together, the phenomena of no interaction (i.e., additive effect) usually occur $(20,53)$. In some cases, antagonistic influence and incompatible mechanism among the agents and measures may be

TABLE 2. Biological characteristics of Fusarium oxysporum f. sp. cucumerinum isolates KW2-1 and KW2-1-F

\begin{tabular}{lccc}
\hline Isolate & $\begin{array}{c}\text { Spores } \\
\left(\times 10^{6} / \text { plate }\right)^{\mathrm{x}}\end{array}$ & $\begin{array}{c}\text { Color value } \\
(\mathrm{U} / \mathrm{ml})^{\mathrm{y}}\end{array}$ & $\begin{array}{c}\text { Glucosaccharase } \\
\text { activity }(\mathrm{U})^{\mathrm{z}}\end{array}$ \\
\hline KW2-1-F & $6.2 \pm 0.4$ & $3.32 \pm 0.09$ & $2.07 \pm 0.63$ \\
KW2-1 & $115.0 \pm 2.6$ & $8.15 \pm 0.06$ & $4.52 \pm 0.18$ \\
\hline
\end{tabular}

${ }^{x}$ Means and standard deviations of spore production of the original strain KW2-1 and the isolate fumigated with $98 \%$ dazomet powder (100 ppm) grown on potato dextrose agar medium at $26^{\circ} \mathrm{C}$ for 7 days with three replicates. The two values are significantly different $(P<0.01)$ according to the $t$ test.

${ }^{y}$ Means and standard deviations of pigment production in the original strain KW2-1 and the isolate fumigated with $98 \%$ dazomet powder (100 ppm) incubated in pigment-producing liquor at $28^{\circ} \mathrm{C}, 200 \mathrm{rpm}$ for 5 days with three replicates. The color value was determined at $520 \mathrm{~nm}$ with an ultraviolet spectrophotometer. The two values are significantly different $(P<$ 0.01 ) according to the $t$ test.

${ }^{z}$ Means and standard deviations of $\beta$-D-glucosaccharase activity in the original strain KW2-1 and the isolate fumigated by $98 \%$ dazomet powder $(100 \mathrm{ppm})$ in potato sucrose broth at $25^{\circ} \mathrm{C}, 120 \mathrm{rpm}$ for 7 days with three replicates. The two values are statistically different at $P=0.015$ according to the $t$ test.

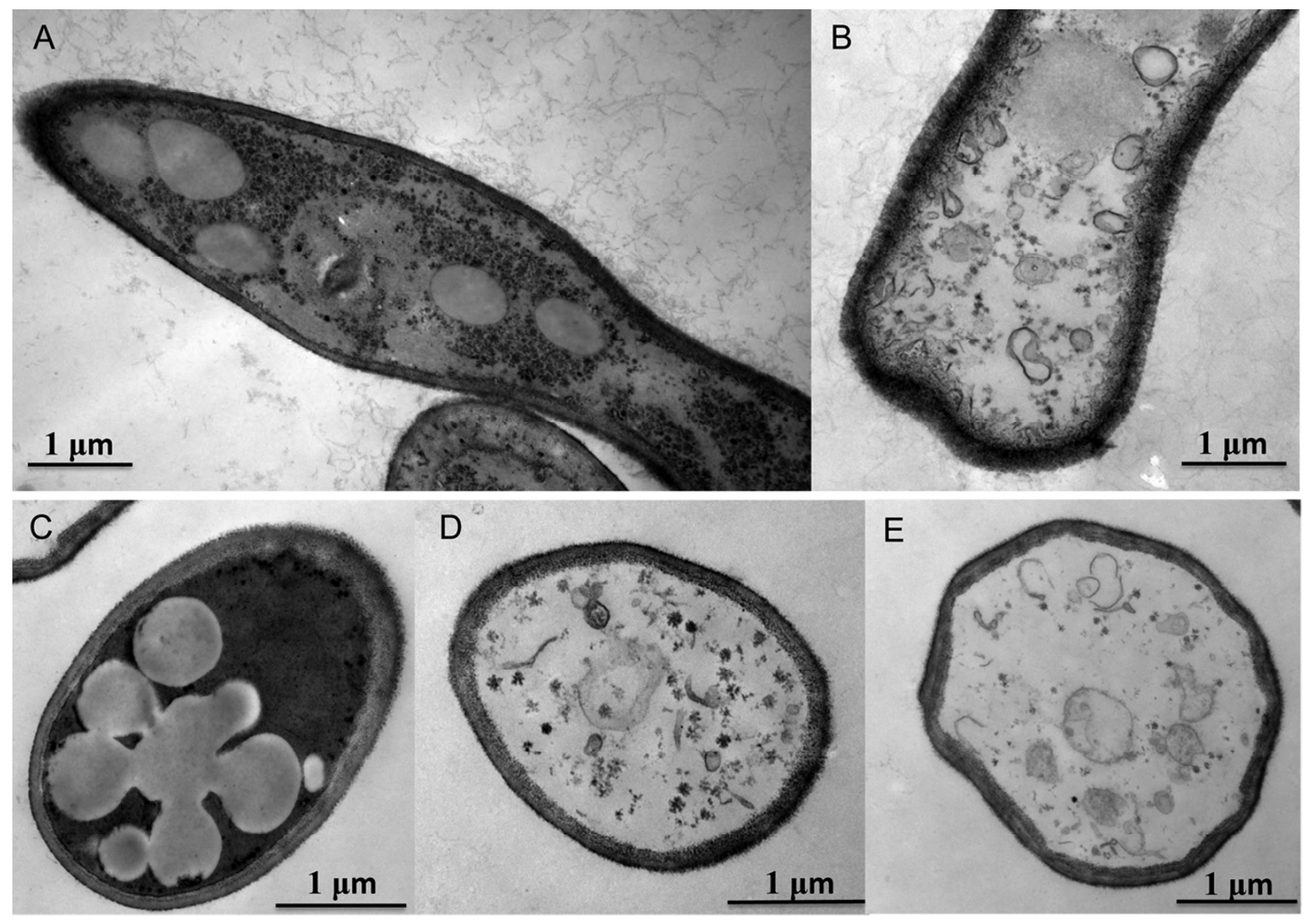

Fig. 2. Microstructure of spores and mycelia of Fusarium oxysporum f. sp. cucumerinum. Isolates KW2-1 and KW2-1-F were grown on potato dextrose agar at $26^{\circ} \mathrm{C}$ for 7 days and observed with a scanning electron microscope (Hitachi S-570). A, Mycelium of KW2-1; B, mycelium of KW2-1-F; C, KW2-1 spore; D and E, KW2-1-F spores. Scale bars represent $1 \mu \mathrm{m}$. 


\section{LITERATURE CITED}

1. Arbel, Z., and Fuentes, C. L. 2007. Accelerated biodegradation of pesticides: An overview of the phenomenon, its basis and possible solutions; and a discussion on the tropical dimension. Crop Prot. 26:17331746.

2. Ashrafi, S. J., Rastegar, M. F., and Saremi, H. 2010. Rosemary wilting disease and its management by soil solarization technique in Iran. Afr. J. Biotechnol. 9:7048-7057.

3. Bliss, C. I. 1956. The calculation of microbial assays. Bacteriol. Rev. 20:243-258.

4. Butt, T. M., Jackson, C., and Magan, N. 2001. Fungi as Biocontrol Agents: Progress, Problems and Potential. CABI Publishing, UK.

5. Che, J. M., Liu, B., Zhu, Y. J., Lan, J. L., Lin, K. M., and Xiao, R. F. 2006. Studies on testing conditions for $\beta$-D-glucosidase activity in Fusarium oxysporum. Acta Jiangxi Agric. Univ. 28:126-129.

6. Cooper, R. M., and Wood, R. K. S. 1975. Regulation of synthesis of cell wall degrading enzymes by Verticillium albo-atrum and Fusarium oxysporum f. sp. lycopersici. Physiol. Plant Pathol. 5:135-156.

7. Copping, L. G. 2004. The Manual of Biocontrol Agents. Third Edition of the BioPesticide Manual. BCPC, Hampshire, UK.

8. Correa, E. B., Bettiol, W., and Morandi, M. A. B. 2010. Biological control of Pythium aphanidermatum root rot and growth promotion of hydroponic lettuce by Clonostachys rosea. Trop. Plant Pathol. 35:248-252.

9. Cota, L. V., Maffia, L. A., Mizubuti, E. S. G., Macedo, P. E. F., and Antunes, R. F. 2008. Biological control of strawberry gray mold by Clonostachys rosea under field conditions. Biol. Control 46:515-522.

10. Cui, T. B., and Liu, Q. X. 2010. Study on liquid fermentation conditions for anthraquinone pigment by Fusarium oxysporum. China Biotechnol. 30:56-61.

11. Cumagun, C. J. R., Bowden, R. L., Jurgenson, J. E., Leslie, J. F., and Miedaner, T. 2004. Genetic mapping of pathogenicity and aggressiveness of Gibberella zeae (Fusarium graminearum) toward wheat. Phytopathology 94:520-526.

12. De Cal, A., Martinez-Treceno, A., Lopez-Aranda, J. M., and Melgarejo, P. 2004. Chemical alternatives to methyl bromide in Spanish strawberry nurseries. Plant Dis. 88:210-214.

13. De Cal, A., Martinez-Treceno, A., Salto, T., Lopez-Aranda, J. M., and Melgarejo, P. 2005. Effect of chemical fumigation on soil fungal communities in Spanish strawberry nurseries. Appl. Soil Ecol. 28:47-56.

14. De Ceuster, H., and Pauwels, F. 1995. Soil disinfestation in the Belgian horticulture-A practice view. ISHS Acta Hortic. 382:37-50.

15. Di Primo, P., Gamliel, A., Austerweil, M., Steiner, B., Beniches, M., Peretz-Alon, I., and Katan, J. 2003. Accelerated degradation of metamsodium and dazomet in soil: Characterization and consequences for pathogen control. Crop Prot. 22:635-646.

16. Duan, G. R., Shi, Y. X., Xie, X. W., Wang, W. W., and Li, B. J. 2010. Fungicides in vitro and in vivo screening against Fusarium oxysporum $\mathrm{f}$. sp. cucumerinum. China Veg. 12:60-65.

17. Elad, Y., Katan, J., and Chet, I. 1980. Physical, biological, and chemical control integrated for soilborne disease in potatoes. Phytopathology 70:418-422.

18. Epstein, L., and Lockwood, J. L. 1984. Effect of soil microbiota on germination of Bipolaris victoriae conidia. Trans. Br. Mycol. Soc. 82:6369.

19. Eshel, D., Gamliel, A., Katan, J., and Grinstein, A. 1999. Evaluation of soil fumigants on soilborne fungal pathogens in a controlled-environment system and in soil. Crop Prot. 18:437-443.

20. Fravel, D. R. 1996. Interaction of biocontrol fungi with sublethal rates of metham sodium for control of Verticillium dahliae. Crop Prot. 15:115119.

21. Fu, C. H., Hu, B. Y., Chang, T. T., Hsueh, K. L., and Hsu, W. T. 2012. Evaluation of dazomet as fumigant for the control of brown root rot disease. Pest Manage. Sci. 68:959-962.

22. Guetsky, R., Shtienberg, D., Elad, Y., Fischer, E., and Dinoor, A. 2002. Improving biological control by combining biocontrol agents each with several mechanisms of disease suppression. Phytopathology 92:976-985.

23. Hao, Z. P., Christie, P., Qin, L., Wang, C. X., and Li, X. L. 2005. Control of Fusarium wilt of cucumber seedlings by inoculation with an arbuscular mycorrhizal fungus. J. Plant Nutr. 28:1961-1974.

24. Ibekwe, A. M., Papiernik, S. K., Gan, J., Yates, S. R., Yang, C. H., and Crowley, D. E. 2001. Impact of fumigants on soil microbial communities. Appl. Environ. Microbiol. 67:3245-3257.

25. Indirani, R., and Jayakumar, R. 2006. Bioefficacy of dazomet in tomato nursery. Indian J. Crop Sci. 1:165-167.

26. Jensen, B., Knudsen, I. M. B., and Jensen, D. F. 2000. Biological seed treatment of cereals with fresh and long-term stored formulations of Clonostachys rosea: Biocontrol efficacy against Fusarium culmorum. Eur. J. Plant Pathol. 106:233-242.
27. Kimura, A., Takano, Y., Furusawa, I., and Okuno, T. 2001. Peroxisomal metabolic function is required for appressorium-mediated plant infection by Colletotrichum lagenarium. Plant Cell 13:1945-1957.

28. Kredics, L., Antal, Z., Manczinger, L., Szekeres, A., Kevei, F., and Nagy, E. 2003. Influence of environmental parameters on Trichoderma strains with biocontrol potential. Food Technol. Biotechnol. 41:37-42.

29. Ma, C. Z., Gu, Z. R., Li, S. D., Liu, X. Z., Miao, Z. Q., Chen, Y. J., Wang, Y., Liu, Y. Z., Feng, G. Q., Xia, Z. Y., and Li, Y. H. 2006. Control efficacy of soil fumigation by Dazomet and K-Vapam on root rot complex in Panax notoginseng continuous cropping field. Acta Agric. Shanghai 22:15.

30. Ma, Y. L., Wu, F. Z., and Liu, S. W. 2008. Pathologic structures of cucumber cultivars with different resistance to Fusarium oxysporum. Plant Prot. 34:81-84.

31. Mao, L. G., Wang, Q. X., Yan, D. D., Xie, H. W., Li, Y., Guo, M. X., and Cao, A. C. 2012. Evaluation of the combination of 1,3-dichloropropene and dazomet as an efficient alternative to methyl bromide for cucumber production in China. Pest Manage. Sci. 68:602-609.

32. Martin, F. N. 2003. Development of alternative strategies for management of soilborne pathogens currently controlled with methyl bromide. Annu. Rev. Phytopathol. 41:325-350.

33. Martin, J. P., Baines, R. C., and Ervin, J. O. 1957. Influence of soil fumigation for citrus replants on the fungus population of the soil. Soil Sci. Soc. Am. J. 21:163-166.

34. Mazzola, M. 2010. Management of resident soil microbial community structure and function to suppress soilborne disease development. Pages 200-218 in: Climate Change and Crop Production. M. P. Reynolds, ed. CABI Publisher, London.

35. Moller, K., Jensen, B., Andersen, H. P., Stryhn, H., and Hockenhull, J. 2003. Biocontrol of Pythium tracheiphilum in Chinese cabbage by Clonostachys rosea under field conditions. Biocontrol Sci. Technol. 13:171-182.

36. Morandi, M. A. B., Maffia, L. A., Mizubuti, E. S. G., Alfenas, A. C., and Barbosa, J. G. 2003. Suppression of Botrytis cinerea sporulation by Clonostachys rosea on rose debris: A valuable component in Botrytis blight management in commercial greenhouses. Biol. Control 26:311317.

37. Moura, L., Queiroz, I., Mourão, I., Brito, L. M., and Duclos, J. 2012. Effectiveness of soil solarization and biofumigation for the control of corky root and root-knot nematode Meloidogyne spp. on tomato. ISHS Acta Hortic. 933:399-405.

38. Omirou, M., Rousidou, C., Bekris, F., Papadopoulou, K. K., Menkissoglou-Spiroudi, U., Ehaliotis, C., and Karpouzas, D. G. 2011. The impact of biofumigation and chemical fumigation methods on the structure and function of the soil microbial community. Microb. Ecol. 61:201-213.

39. Paret, M. L., Sharma, S. K., and Alvarez, A. M. 2012. Characterization of biofumigated Ralstonia solanacearum cells using micro-Raman spectroscopy and electron microscopy. Phytopathology 102:105-113.

40. Pisi, A., Roberti, R., Zakrisson, E., Filippini, G., Mantovani, W., and Cesari, A. 2001. SEM investigation about hyphal relationships between some antagonistic fungi against Fusarium spp. foot rot pathogen of wheat. Phytopathol. Mediterr. 40:37-44.

41. Qiu, M., Zhang, R., Xue, C., Zhang, S., Li, S., Zhang, N., and Shen, Q. 2012. Application of bio-organic fertilizer can control Fusarium wilt of cucumber plants by regulating microbial community of rhizosphere soil. Biol. Fertil. Soils 48:807-816.

42. Rose, S., Parker, M., and Punja, Z. K. 2003. Efficacy of biological and chemical treatments for control of Fusarium root and stem rot on greenhouse cucumber. Plant Dis. 87:1462-1470.

43. Singh, P. P., Shin, Y. C., Park, C. S., and Chung, Y. R. 1999. Biological control of Fusarium wilt of cucumber by chitinolytic bacteria. Phytopathology 89:92-99.

44. Sivan, A., and Chet, I. 1993. Integrated control of Fusarium crown and root rot of tomato with Trichoderma harzianum in combination with methyl bromide or soil solarization. Crop Prot. 12:380-386.

45. Slusarski, C., and Pietr, S. J. 2003. Validation of chemical and nonchemical treatments as methyl bromide replacements in field grown cabbage, celeriac and tomato. Veg. Crops Res. Bull. 58:113-126.

46. Slusarski, C., and Pietr, S. J. 2009. Combined application of dazomet and Trichoderma asperellum as an efficient alternative to methyl bromide in controlling the soilborne disease complex of bell pepper. Crop Prot. 28:668-674.

47. Triky-Dotan, S., Austerweil, M., Steiner, B., Peretz-Alon, Y., Katan, J., and Gamliel, A. 2009. Accelerated degradation of metam-sodium in soil and consequences for root-disease management. Phytopathology 99:362368.

48. Wang, D., Fraedrich, S. W., Juzwik, J., Spokas, K., Zhang, Y., and Koskinen, W. C. 2006. Fumigant distribution in forest nursery soils under water seal and plastic film after application of dazomet, metam-sodium 
and chloropicrin. Pest Manage. Sci. 62:263-273.

49. Wang, Q. X., Yan, D. D., Mao, L. G., Ma, T. T., Liu, P. F., Wu, Z. F., Li, Y., Guo, M. X., and Cao, A. 2013. Efficacy of 1,3-dichloropropene plus chloropicrin gelatin capsule formulation for the control of soilborne pests. Crop Prot. 48:24-28.

50. Wang, Z. Y., Soanes, D. M., and Kershaw, M. J. 2007. Functional analysis of lipid metabolism in Magnaporthe grisea reveals a requirement for peroxisomal fatty acid $\beta$-oxidation during appressorium-mediated plant infection. Mol. Plant-Microbe Interact. 20:475-491.

51. Wu, M., Zhang, H., Li, X., Zhang, Y., Su, Z., and Zhang, C. 2008. Soil fungistasis and its relations to soil microbial composition and diversity: A case study of a series of soils with different fungistasis. J. Environ. Sci. 20:871-877.

52. Xiao, R. F., Lan, J. L., Che, J. M., Liu, B., and Liu, D. Y. 2008. Study on the correlation between the activity of $\beta$-D glucosidase and the pathogenicity of Fusarium oxysporum strains from cucurbitaceous crops. Chin. Agric. Sci. Bull. 24:351-355.

53. Xu, X. M., Jeffries, P., Pautasso, M., and Jeger, M. J. 2011. Combined use of biocontrol agents to manage plant diseases in theory and practice. Phytopathology 101:1024-1031.

54. Yang, C. 2012. Investigation of sodium tetrathiocarbonate as a potential fumigant for vegetable soilborne disease management and its effect on soil biological environment. Dissertation, Graduate School of Chinese Academy of Agricultural Sciences, Beijing.

55. Zhang, Y. H., Gao, H. L., Ma, G. Z., and Li, S. D. 2004. Mycoparasitism of Gliocladium roseum 67-1 on Sclerotinia sclerotiorum. Acta Phytopathol. Sin. 34:211-214.

56. Zhang, Y. H., Li, S. D., Wang, G. Q., Otsu, Y., and Wang, Z. Y. 2007. Biological control of soybean Sclerotinia rot with wettable powder of Gliocladium. Acta Phytopathol. Sin. 33:141-142. 